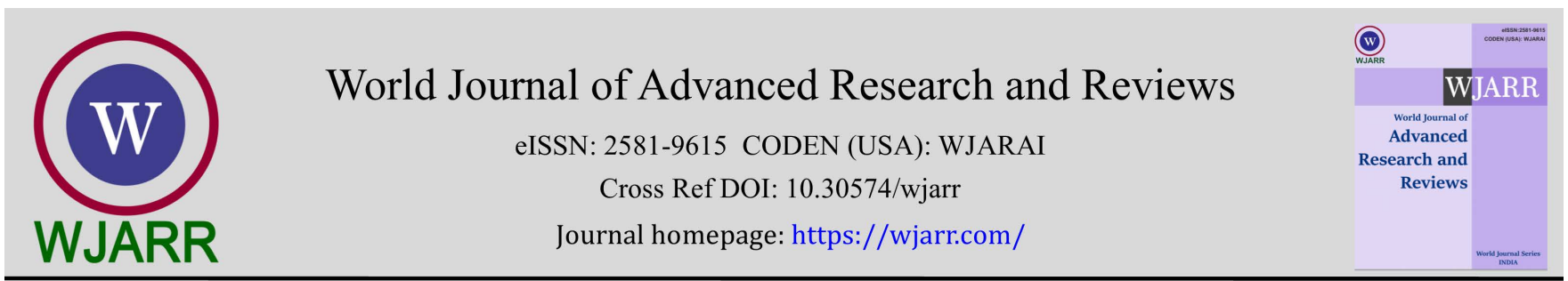

(RESEARCH ARTiClE)

Check for updates

\title{
Public education expenditure and economic growth : based on panel data from 2009 to 2019 in China
}

\author{
Yao Liu, Ziru Tan and Xiaohua Ning * \\ Central university of finance and economics, Beijing, China.
}

World Journal of Advanced Research and Reviews, 2021, 11(02), 184-192

Publication history: Received on 09 July 2021; revised on 14 August 2021; accepted on 16 August 2021

Article DOI: https://doi.org/10.30574/wjarr.2021.11.2.0376

\begin{abstract}
Public education expenditure is the largest public expenditure and the foundation of education development in China. This paper uses Cobb-Douglas production function model to analyze the relationship between public education expenditure and China's economic growth, and explores the impact of the proportion of public education expenditure in primary, secondary and tertiary education expenditure on economic growth. The results show that public education expenditure has a positive effect on economic growth, and that secondary education accounts for the largest contribution to economic growth, followed by higher education and primary education. The research results suggest that China should increase financial investment in education and optimize the expenditure structure of three-level education.
\end{abstract}

Keywords: Public education expenditure; Three-level education expenditures; Economic growth; China

\section{Introduction}

Education is a cause of decisive significance to the great rejuvenation of the Chinese nation. The 19th National Congress of the Party pointed out that priority should be given to the development of education, run pre-school education well, popularize high school education, speed up the construction of first-class universities and disciplines, and realize the connotative development of higher education. The development of education cannot be separated from the support of national public education expenditure which refers to the government expenditure for maintaining and developing various educational undertakings. Xinyu Zhan, Wenbin Liu believes that for a country like China, where the government plays a major role in education, an intuitive way to measure the importance of education to economic development is from a financial perspective [1].

In theory, the endogenous growth theory internalizes the human capital factor, and holds that education is the basic project to improve the national quality and realize the country's prosperity. Education promotes economic growth by improving labor productivity. However, Ying Li analyzed foreign studies and found that there is no final conclusion on whether education expenditure can promote economic growth [2]. In addition, the rationality of public education expenditure-the share of investment in primary, secondary and tertiary education expenditure-has an important impact on the effectiveness of fiscal expenditure when the total public education expenditure is fixed and limited.

At present, China's economic and social development has entered a new normal and a critical period of economic transformation, which requires sustainable and high-quality economic development. What is the relationship between public education expenditure and economic growth? In the future, what role will education play in China's economic development? How should China give full play to the benefits of public education expenditure? Under such a background

\footnotetext{
* Corresponding author: Xiaohua Ning

Central university of finance and economics, Beijing, China.
}

Copyright (c) 2021 Author(s) retain the copyright of this article. This article is published under the terms of the Creative Commons Attribution Liscense 4.0. 
of the times, it is of great practical significance to empirically analyze the relationship between public education expenditure and economic growth and to explore the impact on economic growth of the proportion of public education expenditure in primary, secondary and tertiary education expenditure.

\section{The theoretical analysis of public education expenditure to promote economic growth}

Education plays a huge role in promoting economic growth, and education investment is an important guarantee for education to play its role. Since the reform and opening up, China has risen up and China's economy has taken on a thriving appearance, which is closely related to the Party and the state's high attention to the development of education. Based on the research of Lucas and Schultz, the effect of education on economic growth includes internal effect and spillover effect, and internal effect refers to the effect of individual human capital on their productivity [2].

Human capital is the embodiment of labor force quality, which is represented by the sum of all kinds of production knowledge, labor and management skills and health quality. In the 1960s, American economists Schultz and Becker founded the human capital theory, which broke the traditional economic theory that material capital is the main driving force for economic growth. The theory holds that the role of human capital is greater than that of material capital in the process of economic growth, and that education investment is an important force to improve human capital. Among them, the ownership of human capital is mainly determined by education level and health status.

Education in China is booming, but there is still room for improvement in the allocation and investment of education. According to estimates by Jianfang Yang and others, the contribution of China's material capital accumulation was $58.2 \%$, the contribution of human capital accumulation was $16.8 \%$, and the total contribution of human capital stock and technological level was 39.9\% between 1985 and 2000 [4]. During this period, the cumulative contribution rate of human capital was far less than that of material capital. In fact, human capital can promote economic growth, and its marginal impact on economic growth is greater than that of material capital. However, due to its low investment and long return cycle, the contribution rate of human capital is low at this stage. In addition, the large difference in education investment between urban and rural areas and between regions has caused the problem of education inequality, affecting the return on human capital of the residents, which in turn further affects the investment in human capital, all of which may increase the income gap, laying hidden dangers for the steady and healthy growth of the economy. Education funds are an important guarantee for the development of education. China's education industry has developed steadily and healthily. In recent years, the proportion of government expenditure on education in GDP has gradually increased, but the proportion of government expenditure on education still lags behind that of developed countries: in 2019, the total government expenditure on education in China accounted for 3.5\% of GDP. In 2017, the total government expenditure on education in Japan, Australia and the United Kingdom accounted for 3.2\%, 5.1\% and $5.4 \%$ of GDP respectively In the United States, it reached $5.0 \%$ as early as 2014 .

As for the spillover effect of education, it can be considered that while individuals receive economic and non-economic benefits from education, some of the benefits will benefit other sectors of society. Such as the reduction of social crime rate and the improvement of social well-being under the effect of educational spillover. With the improvement of social and cultural level, the overall legal awareness will be correspondingly improved. At the same time, education level and income are often positively correlated, which also means that with the improvement of social and cultural level, the opportunity cost of crime will be higher, thus reducing the social crime rate. In addition, due to the improvement of social and cultural level, the overall social culture, civilization level and Johnson's awareness of fitness will also be improved, which can promote the development of social science and culture and the formation of a harmonious society, and is also conducive to the improvement of life expectancy, thus enhancing the well-being of the residents in the society [2]. In fact, it is not difficult to imagine that the decrease of social crime rate and the improvement of social wellbeing are also beneficial to economic growth.

\section{China's public education expenditure status analysis}

\subsection{Total public education expenditure}

The scale of public education expenditure reflects the importance the national government attaches to education. During the period of 2009-2019, China's economic development has entered the fast lane, and the total public education expenditure has been increasing. As shown in Table 1, the state's financial expenditure on education increased from $1,223.109$ billion yuan in 2009 to 400.655 billion yuan in 2019, an increase of about 3.3 times in ten years. In addition, the relative scale of public education expenditure (i.e. the proportion of public education expenditure to GDP) has remained basically stable. As can be seen from Table 1, from 2009 to 2012, the relative scale of public education 
expenditure increased year by year, reaching the $4 \%$ threshold in 2012 . Since then, China's fiscal education expenditure has remained stable at more than $4 \%$ of GDP for eight consecutive years, achieving the target of 4\% of GDP for national fiscal education expenditure as proposed in the "Outline of China's Education Reform and Development" in 1993.

Table 1 China's National Fiscal Expenditure on Education and Its Proportion to GDP from 2009 to 2019.

\begin{tabular}{|c|c|c|}
\hline Year & $\begin{array}{l}\text { The national financial expenditure } \\
\text { on education (100 million yuan) }\end{array}$ & $\begin{array}{c}\text { Proportion of National Fiscal } \\
\text { Expenditure on Education to GDP }\end{array}$ \\
\hline 2009 & 12231.09 & $3.59 \%$ \\
\hline 2010 & 14670.07 & $3.66 \%$ \\
\hline 2011 & 18586.70 & $3.93 \%$ \\
\hline 2012 & 23147.57 & $4.28 \%$ \\
\hline 2013 & 24488.22 & $4.30 \%$ \\
\hline 2014 & 26420.58 & $4.15 \%$ \\
\hline 2015 & 29221.45 & $4.26 \%$ \\
\hline 2016 & 31396.25 & $4.22 \%$ \\
\hline 2017 & 34207.75 & $4.14 \%$ \\
\hline 2018 & 36995.77 & $4.11 \%$ \\
\hline 2019 & 40046.55 & $4.04 \%$ \\
\hline
\end{tabular}

Table 2 Proportion of World and High-Income Countries' Public Education Expenditure to GDP, 2001-2010

\begin{tabular}{|c|c|c|}
\hline Year & $\begin{array}{l}\text { Share of world public education } \\
\text { expenditure in GDP }\end{array}$ & $\begin{array}{l}\text { Public education expenditure as a } \\
\text { proportion of GDP in high-income countries }\end{array}$ \\
\hline 2001 & $4.08 \%$ & $4.96 \%$ \\
\hline 2002 & $4.02 \%$ & $5.01 \%$ \\
\hline 2003 & $4.17 \%$ & $5.08 \%$ \\
\hline 2004 & $4.03 \%$ & $5.04 \%$ \\
\hline 2005 & $4.13 \%$ & $4.95 \%$ \\
\hline 2006 & $4.22 \%$ & $4.91 \%$ \\
\hline 2007 & $4.24 \%$ & $4.71 \%$ \\
\hline 2008 & $4.40 \%$ & $4.90 \%$ \\
\hline 2009 & $4.67 \%$ & $5.11 \%$ \\
\hline 2010 & $4.59 \%$ & $5.40 \%$ \\
\hline
\end{tabular}

Table 2 shows the ratio of public education expenditure to GDP in the world and high-income countries from 2001 to 2010. Judging from the international comparison, the relative scale of public education investment in China in 2019 is equivalent to the level of the world 20 years ago. According to World Bank statistics, the ratio of public education expenditure to GDP in high-income countries such as the United States and Japan reached 4.8\% in 2001. From this, we can see that although the total public education expenditure in China has increased steadily, the investment is still insufficient. Compared with the world average level and the developed countries, there is still a big gap. For a long time, China has taken GDP growth as an important indicator to measure the government's achievements. Due to the slow effect of the funds invested in education, a large amount of fiscal expenditure is used for other investments, which is an important reason for the insufficient investment in public education. The development of education cannot meet the 
needs of the people, and the investment in education cannot keep pace with the social and economic development, which will restrict the sustainable development of the economy.

\subsection{The hierarchy of public education expenditures}

The hierarchical structure of public education expenditure refers to the proportion of financial education expenditure allocated among primary, secondary and tertiary education expenditure respectively. The expenditure structure is related to the state's emphasis on each level of education and educational benefits. It is particularly important to allocate the three levels of education expenditure in a reasonable proportion when the total public education expenditure is fixed and limited.

Statistics Report on the Implementation of National Education Funds in 1995 shows that the ratio of the average cost of primary, secondary and higher education students in China is 1: 2.28: 20.43, which is 1: 1.7: 8 in developing countries and 1: 1.1: 4.3 in developed countries [5]. This indicates that the public finance expenditure in China was excessively inclined to higher education at the end of last century. Table 3 shows the ratio of average public expenditure of tertiary education students in China from 2009 to 2019. In 2009, the ratio of the average cost of students in primary and secondary education in China was 1: 1.24: 2.54, and in 2019, the ratio was 1: 1.46: 1.96. During the past ten years, the gap between the average public expenditure of students in tertiary education gradually narrowed, indicating that the government has increased its investment in primary and secondary education, and the hierarchical structure of public education expenditure tends to be reasonable. According to economic experts, as a developing country, the reasonable allocation of educational finance in tertiary education should be 1.5: 1: 0.6 [6]. However, it is worth noting that from 2009 to 2019, the average investment of higher education students in China was about twice that of primary education. In the new era, China's development needs to cultivate high-caliber talents. However, basic education is the foundation for realizing the great rejuvenation of the Chinese nation and building a modern socialist power. Therefore, the investment in primary and secondary public education in China still needs to be increased.

Table 3 Proportion of China's Primary, Secondary and Higher Education Expenditure from 2009 to 2019

\begin{tabular}{|l|c|}
\hline Year & Proportion of expenditure on primary, secondary and higher education \\
\hline 2009 & $1: 1.24: 2.54$ \\
\hline 2010 & $1: 1.23: 2.39$ \\
\hline 2011 & $1: 1.27: 2.79$ \\
\hline 2012 & $1: 1.29: 2.67$ \\
\hline 2013 & $1: 1.29: 2.26$ \\
\hline 2014 & $1: 1.27: 2.10$ \\
\hline 2015 & $1: 1.30: 2.05$ \\
\hline 2016 & $1: 1.35: 1.96$ \\
\hline 2017 & $1: 1.39: 1.99$ \\
\hline 2018 & $1: 1.45: 1.96$ \\
\hline 2019 & $1: 1.46: 1.96$ \\
\hline
\end{tabular}

The proportion of tertiary education is calculated from the average public budget education funds of lower education, secondary education and higher education students, in which the average public budget education funds of lower education and higher education students are expressed by the average public budget education funds of ordinary primary schools and ordinary higher schools respectively, and the average public budget education funds of secondary education students are calculated by weighting the average education funds of ordinary junior middle schools, ordinary high schools and secondary vocational schools according to the number of students in school. Ordinary primary school, ordinary junior high school, ordinary high school, secondary vocational school, ordinary higher school students are generally public budget education funds, and the corresponding number of students in school. 


\section{Empirical Research}

\subsection{Model building}

This paper selects the contribution rate of education to economic growth as an indicator to depict the relationship between public education and economic growth in China. Considering China's four-level and seven-level education system, this paper starts with the employed people with different education levels to express the contribution rate of education to economic growth, and divides the employed people into the employed people with primary education level, the employed people with secondary education level and the employed people with higher education level according to their education level.

The model assumes that the influencing factors of production include capital, labor and technological level; Capital and labor can replace each other; The remuneration of scale remains unchanged.

The Cobb-Douglas production function can analyze the economic growth through the factors of capital input, labor quantity input and technology level. The general form of the Cobb-Douglas production function is:

$$
Y_{t}=A_{t} K_{t}^{\alpha} L_{t}^{\beta}
$$

Where $\mathrm{Y}$ is the output, $\mathrm{A}$ is the level of technology, $\mathrm{K}$ is capital, $\mathrm{L}$ is the number of labor, $\alpha$ is the elasticity coefficient of capital output, $\beta$ is the elasticity coefficient of labor output, $t$ is time and $\alpha+\beta=1$.

This production function is one of the most widely used production functions in economics and plays an important role in mathematical economics. However, the production function only pays attention to the factors of labor force quantity and ignores the influence of labor force quality. Based on the theory of human capital, this paper deals with $\mathrm{L}$ and proposes a new production function.

$$
Y_{t}=A_{t} K_{t}^{\alpha}\left(L_{o t} E_{t}\right)^{\beta}
$$

Among them, $\mathrm{L}_{\mathrm{ot}}$ is the initial labor force and $\mathrm{E}_{\mathrm{t}}$ is the investment in education.

The logarithm of equation (2) and the derivative of $t$ are:

$$
y=a+\alpha k+\beta l_{0}+\beta e
$$

Where y represents the annual economic growth rate, a represents the rate of technological progress, k represents the annual growth rate of capital input, $l_{0}$ represents the annual growth rate of initial labor input, and e represents the annual growth rate of education input.

The contribution of education to economic growth is as follows:

$$
C_{e}=\frac{\beta \mathrm{e}}{\mathrm{y}}
$$

The contribution of all levels of education to economic growth is:

$$
R=E * C_{e}
$$

Where $\mathrm{R}$ is the contribution rate of all levels of education to economic growth, and $\mathrm{E}$ is the percentage of all levels of education to the annual average growth rate of the comprehensive education index. At the same time, the article will use the elasticity coefficient of labor output estimated by Denison in the 1960s according to the US economy, which is 0.73 , i.e. for every $1 \%$ increase in labor input, the output will increase by $0.73 \%$. 


\subsection{Empirical analysis}

\subsubsection{Determine the comprehensive education index of employed persons at all levels in 2009 and 2019}

According to Xiao Ma and Lang Xu Error! Reference source not found., the simplified labor coefficient is 1 for primary school, 1.38 for junior high school, 1.72 for senior high school and 2.34 for junior high school and above Error! Reference source not found.. Based on Table 1, the following formula is used:

Per capita length of I education = proportion of employed persons with I and above education * length of I education $/ 100$.

( $I=1,2,3,4,5$, representing primary school, junior high school, senior high school, college, undergraduate, postgraduate and above, with corresponding education years of 6,3,3,4,2 respectively)

The calculated years of schooling for each stage of education in 2009 and 2019 are shown in Table 5

Table 4 Composition of Education Levels of Employed Persons in 2009 and 2009 (\%)

\begin{tabular}{|c|c|c|c|c|c|}
\hline Year & $\begin{array}{l}\text { Primary } \\
\text { school }\end{array}$ & $\begin{array}{l}\text { Junior high } \\
\text { school }\end{array}$ & $\begin{array}{l}\text { High } \\
\text { school }\end{array}$ & $\begin{array}{l}\text { College and } \\
\text { undergraduate }\end{array}$ & $\begin{array}{l}\text { Postgraduate } \\
\text { and above }\end{array}$ \\
\hline 2009 & 26.3 & 48.7 & 12.8 & 7.2 & 0.23 \\
\hline 2019 & 15.7 & 40.6 & 18.7 & 21.7 & 1.1 \\
\hline
\end{tabular}

Data sources: China Statistics Press, China Statistical Yearbook 2020 and China Statistical Yearbook 2010.

Table 5 Years of schooling of employed persons in each stage in 2009 and 2019 (years)

\begin{tabular}{|c|c|c|c|c|c|}
\hline Year & $\begin{array}{l}\text { Primary } \\
\text { school }\end{array}$ & $\begin{array}{l}\text { Junior high } \\
\text { school }\end{array}$ & $\begin{array}{l}\text { High } \\
\text { school }\end{array}$ & $\begin{array}{l}\text { College and } \\
\text { undergraduate }\end{array}$ & $\begin{array}{l}\text { Postgraduate } \\
\text { and above }\end{array}$ \\
\hline 2009 & 5.7138 & 2.0679 & 0.6069 & 0.2972 & 0.0046 \\
\hline 2019 & 5.868 & 2.463 & 1.245 & 0.912 & 0.022 \\
\hline
\end{tabular}

The average comprehensive education index for 2009 is:

$\mathrm{E}_{0}=5.7138+1.38 \times 2.0679+1.72 \times 0.6069+2.34 \times 0.3018=10.317582$ 。

The average comprehensive education index for 2019 is:

$\mathrm{E}_{1}=5.868+1.38 \times 2.163+1.72 \times 1.245+2.34 \times 0.934=13.5939$ 。

The calculated average comprehensive education index increased by $2.80 \%$ annually in the 10 years from 2009 to 2019 , the primary education index increased by an average of $0.27 \%$ per annum, the secondary education index increased by an average of 3.58\% per annum, the higher education index grew by an average of $11.96 \%$ a year. Obviously, the higher education index has the fastest annual average growth, but due to its relatively small number of years of schooling per capita, it has little impact on the average comprehensive education index.

\subsubsection{Calculate the contribution of all levels of education to economic growth}

This paper uses the growth rate of constant GDP to express the economic growth. Using the statistical yearbook data, taking 1978 as the base period, the GDP indices of 2009 and 2019 are 1873.8 and 3929.2, and the annual average growth rate of real GDP from 2009 to 2019 is calculated as $7.69 \%$. Combined with formula (4), the contribution rate of education to economic growth is $26.58 \%$. In reality, the quality of labor is not only affected by the education level. According to relevant research, the improvement in education level accounts for $60 \%$ of the improvement in human capital [7]. Therefore, the actual contribution rate to the economy based on the original result multiplied by 0.6 is $15.95 \%$.

The steps for calculating the percentage of higher education to the average annual growth rate of the average education index are as follows: 
Education index value excluding higher education:

In $2009, \mathrm{E}_{0}^{\prime}=5.7138+1.38 \times 2.0679+1.72 \times 0.6069=9.61137$;

In $2009, \mathrm{E}_{1}{ }^{\prime}=5.868+1.38 \times 2.163+1.72 \times 1.245=11.40834$;

The average annual growth rate of the education index excluding higher education is $1.73 \%$.

The percentage of higher education received in the average annual growth rate of the education index is $E_{\mathrm{h}}=[(2.80$ $1.73) / 2.80] * 100 \%=38.21 \%$.

Similarly, the average annual growth rate of the education index excluding secondary and higher education is $0.27 \%$. The percentage of secondary and higher education in the average annual growth rate of the education index is $90.36 \%$, thus the percentage of secondary education in the average annual growth rate of the education index is $52.15 \%$. Primary education is $9.64 \%$. According to formula (5), the contribution rate of education to economic growth in China from 2009 to 2019 is $15.95 \%$. The contribution rates of primary, secondary and higher education to economic growth are $1.54 \%$, $8.32 \%$ and $6.09 \%$ respectively. The contribution rate of secondary education to economic growth is the largest, higher education is the second, and primary education is the smallest.

\section{Results}

Primary education is the foundation of secondary and higher education. In recent years, the net enrollment rate of primary education in China tends to be saturated and the growth rate is low. Therefore, the contribution rate of primary education calculated by this method is low. At the same time, it can be seen that the contribution rate of secondary education to the economy is relatively high. Besides, some studies believe that increasing the investment in compulsory education, especially in junior high school education, can effectively narrow the income gap between urban and rural areas [9]. In light of the current situation in China, optimizing the management of secondary education may become a key direction for steady economic growth.

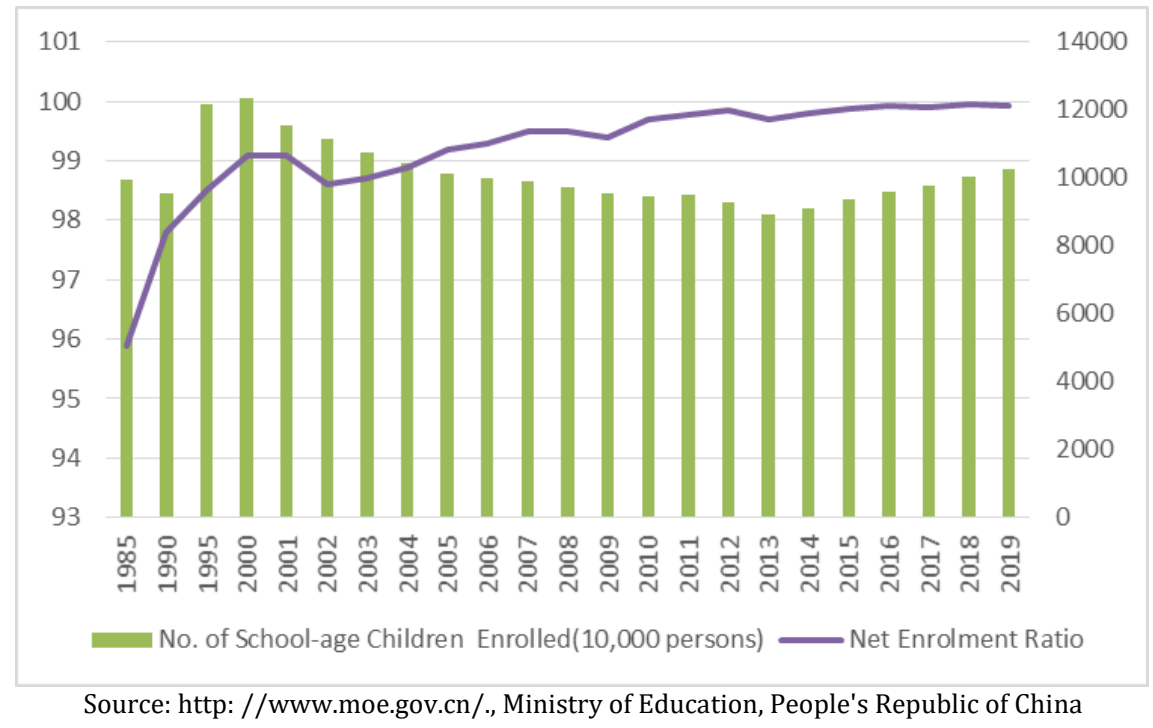

Figure 1 Primary school enrolment and net enrolment ratio

From 1982 to 1990 , the contribution rate of education to the annual average growth rate of GNP was 8.84\%, while that of higher education was only $0.48 \%$ [7]. from 2001 to 2011, the contribution rate of education to GDP growth was $14.83 \%$, and that of higher education was 3.62\%[9]. This paper uses the same method to calculate the contribution rate of education to economic growth from 2009 to 2019 , which is $15.93 \%$ and that of higher education is $6.08 \%$. It can be seen that the contribution rate of education, especially higher education, to economic growth has increased year by year. Under the realistic background of the Chinese economic transformation, the growth of total investment in education may face certain pressure. How to optimize the structure of investment in education at all levels will become a top priority. 


\section{Conclusion}

Based on the analysis of the relationship between public education expenditure and economic growth in China, this paper holds that public education expenditure has a positive effect on economic growth, and secondary education accounts for the largest contribution to economic growth, followed by higher education and primary education. Based on the above results, this paper puts forward the following suggestions on public education expenditure in China:

\subsection{Increase financial investment in education to improve the quality of economic growth}

Although China's total public education expenditure has been growing steadily, there is still a gap compared with the developed countries in the world. Education has a positive external effect and can comprehensively improve the quality of labor force and human resources, which is an important driving force to improve economic efficiency and overall national strength. At present, China's economic and social development has entered a new normal. China should devote itself to transforming a large population country into a strong human resources country, release the potential of human resources, and develop an intensive economy by improving the quality of workers, so as to realize a healthy and steady economic development. In addition, knowledge innovation, technological innovation and industrialization of high and new technologies are the core of the competition in the comprehensive national strength of various countries in the world today, which cannot be separated from the support of education.

Education can be divided into compulsory education and other education. As a pure public good, compulsory education is undertaken by the state finance, while other education as a quasi-public good is mainly undertaken by the government and the beneficiaries. Therefore, the development of education mainly depends on the support of the state finance. The "Education Law" explicitly requires that "three growth" be guaranteed, that is, the proportion of public education expenditure in the gross national product should be steadily increased with the development of the national economyThe proportion of public education expenditure to the total fiscal expenditure at all levels should be gradually increased with the development of the national economyThe growth of education investment of governments at all levels should be higher than the growth of recurrent revenue. However, some researchers have pointed out that there are some problems in the division of the financial and expenditure responsibilities between the central government and the local government, such as the unequal responsibilities and the nonstandard system construction, which to a certain extent leads to the shortage of financial and educational expenditure. Therefore, the central government should do a good job in the overall planning of public education expenditure, clarify the responsibilities of all levels of government education expenditure, implement the "three growth" policy, and ensure the coordinated development of education and economy.

\subsection{Optimize the expenditure structure of tertiary education}

Through the above empirical analysis, it can be seen that secondary education has the largest contribution to economic growth, followed by higher education and primary education. Combined with the national conditions of the developing countries in China, primary education is the basic project to improve the national quality, and the cultivation of talents in secondary education plays an important role in improving the national quality as a whole. Under the condition that the total public education expenditure is limited, it is an unreasonable allocation of resources to invest too much financial education funds in higher education with low economic contribution rate, which reduces the benefit of financial expenditure. However, optimizing the hierarchy of education expenditure does not mean blindly increasing secondary education expenditure. Although the contribution rate of higher education to economic growth in tertiary education is relatively low, the contribution rate of higher education to economic growth has increased year by year, which means that higher education has great potential to promote economic growth. In addition, although primary education has the lowest contribution rate to economic growth, primary education is the foundation of secondary and higher education, and primary education should be provided with adequate financial security. Therefore, China should increase the proportion of primary and secondary education expenditure on the premise of ensuring higher education expenditure. On the one hand, it ensures the financial guarantee of compulsory education and increases the financial input of compulsory education. On the other hand, the state's financial expenditure is limited, which encourages enterprises to cooperate with colleges and universities to promote diversified and market-oriented investment and financing of higher education. 


\section{Compliance with ethical standards}

\section{Acknowledgments}

This work was supported by the Central University of Finance and Economics. The authors are also grateful to the teacher Wang Huijuan of the School of Statistics and Mathematics of CUFE.

\section{Disclosure of conflict of interest}

All authors declare that No conflict of interest in this work.

\section{References}

[1] Xinyu Zhan, Wenbin Liu. Research on the Quality Effect of Economic Growth of China's Fiscal Expenditure on Education-Based on the Perspective of "Five Development Ideas" [J]. Education and Economy. 2019; 01: 46-57.

[2] Ying Li. An Empirical Analysis of the Relationship between Public Education Expenditure and Economic Growth in China: Based on the Perspective of Fiscal Education Expenditure [J]. Journal of Shanxi Finance and Taxation College. 2011; 13(06): 3-6.

[3] Zengzheng Cai. On the Internal and External Benefits of Education [J]. Jiangsu Higher Education. 2001; 4(04): 3336.

[4] Jianfang Yang, Liutang Gong, Qinghua Zhang. Human Capital Formation and Its Impact on Economic Growth: An Endogenous Growth Model with Education and Health Investment and Its Test [J].

[5] Bingzhao Wang, Shi Kecan. 30 Years of China's Education Reform: Basic Education Volume [M]. Beijing: Beijing Normal University Press. 2009; 96.

[6] Ruiyuan Cheng. Analysis of the Current Situation of China's Financial Expenditure on Education and Countermeasures [J]. Knowledge Economy. 2014; 14: 94-95.

[7] Xiao Ma, Lang Xu. The Contribution of Education to Economic Growth: A Comparison between East and West [J].

[8] Yuping Cui. Contribution of China's Higher Education to Economic Growth Rate [J]. Education and Economy. 2001; 4(01): 1-5.

[9] Li Xin, Huijuan Guan. Investment in education at all levels, labor transfer and income gap between urban and rural residents [J]. Statistical Research. 2018; 35(03): 80-92.

[10] Tianping Yang, Zhaoxin Liu. Analysis and comparison of the contribution rate of China's higher education to economic growth [J]. University education management. 2014; 8(03): 7-16. 